\title{
Giant recurrent dumbbell-shaped hypoglossal schwannoma in an elderly male: A case report
}

\author{
ZHIYUN YU ${ }^{1}$, GANG ZHAO $^{1}$, ZHONGYING ZHAO $^{2}$, YUNQIAN LI $^{1}$ and GUIFANG XIE ${ }^{3}$ \\ ${ }^{1}$ Department of Neurosurgery, First Hospital of Jilin University, Changchun, Jilin 130021; \\ ${ }^{2}$ Department of Neurosurgery, Siping Central People's Hospital, Siping, Jilin 136000; \\ ${ }^{3}$ Department of Obstetrics and Gynecology, First Hospital of Jilin University, Changchun, Jilin 130021, P.R. China
}

Received October 29, 2014; Accepted August 5, 2015

DOI: $10.3892 / \mathrm{ol} .2015 .3911$

\begin{abstract}
Dumbbell-shaped hypoglossal Schwannomas of the 12 th cranial nerve are extremely rare, and complete removal of these tumors is difficult, particularly in elderly patients with recurrent tumors. The present study reports the case of a 61-year-old male with a giant recurrent dumbbell-shaped hypoglossal schwannoma that arose extracranially. The recurrent tumor was completely removed in a one-stage surgical procedure via the far lateral suboccipital approach in combination with the transcervical approach. To the best of our knowledge, such a lesion has not been reported previously. The life expectancy and natural course of the disease are important factors to take into account when considering the individual end-point of surgery in patients. More studies on hypoglossal schwannomas are required, particularly cases in which the hypoglossal schwannoma was not totally resected, not only in order to develop more definitive and secure surgical treatments, but also to reduce the resultant unnecessary suffering of patients.
\end{abstract}

\section{Introduction}

Hypoglossal schwannomas are rare, and were reported for the first time by De Martel et al (1) in 1933. The most common symptoms are unilateral tongue atrophy and fasciculation (2) and the disease has been found to exhibit a female predominance (3). Magnetic resonance imaging (MRI) is considered superior to computed tomography for the diagnosis of skull

Correspondence to: Mr. Yunqian Li, Department of Neurosurgery, First Hospital of Jilin University, 71 Xinmin Street, Changchun, Jilin 130021, P.R. China

E-mail: 287348042@qq.com

Miss. Guifang Xie, Department of Obstetrics and Gynecology, First Hospital of Jilin University, 71 Xinmin Street, Changchun, Jilin 130021, P.R. China

E-mail: 664857729@qq.com

Key words: hypoglossal schwannoma, dumbbell-shaped, elderly, recurrent, far lateral approach base tumors, as MRI accurately demonstrates the relationship between tumor location and the surrounding soft tissues (4). Although 39 cases of dumbbell-shaped, hypoglossal schwannoma have been described in the literature to date (3,5-15), only a small proportion of these cases $(<30 \%)$ achieved a complete tumor resection (12), and no recurrent cases were reported. At present, the standard surgical technique used for the treatment of hypoglossal schwannomas is the far lateral approach with partial resection of the condyle, which exposes the hypoglossal canal $(3,16)$. Complete tumor resection is difficult due to intradural and extradural growth through the enlarged hypoglossal canal. A further challenge for surgical treatment is being able to achieve a radical resection and decrease the risk of recurrence at the same time as preserving lower cranial nerve function (9). It is occasionally difficult to decide which management strategies should be used for benign cranial base tumors in patients (10), particularly in elderly patients with recurrent dumbbell-shaped hypoglossal schwannoma. The present study reports the case of an elderly patient with a giant recurrent dumbbell-shaped hypoglossal schwannoma that arose extracranially, to the best of our knowledge, this is the largest case of hypoglossal schwannoma that has been completely removed in a one-stage surgical procedure.

\section{Case report}

A 61-year-old male presented with a cough after drinking water, which had persisted for 8 months, accompanied by hoarseness for the last 4 months. The patient first visited the local Ear, Nose and Throat Department in January 2013, and a neurological examination showed only left hypoglossal mild palsy with hemiatrophy of the tongue. High-resolution computed tomography (CT) scans showed a mass located in the left parapharyngeal space (Fig. 1). The bulk of the tumor was resected via a purely endoscopic transoral approach. Histopathology revealed a relatively cellular schwannoma. The symptoms showed marked improvement following the surgery. The patient was discharged without any further treatment.

In July 2013 the patient presented with the same symptoms and a worse overall condition. An egg-sized mass was found in the left anterior region of the neck. Neurological examination showed left hypoglossal palsy with marked hemiatrophy of the 
A

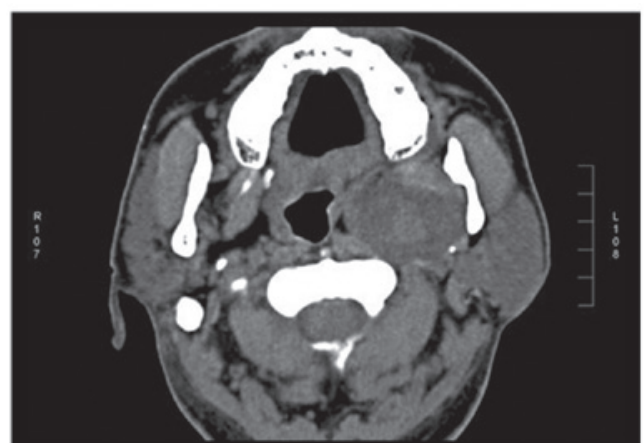

B

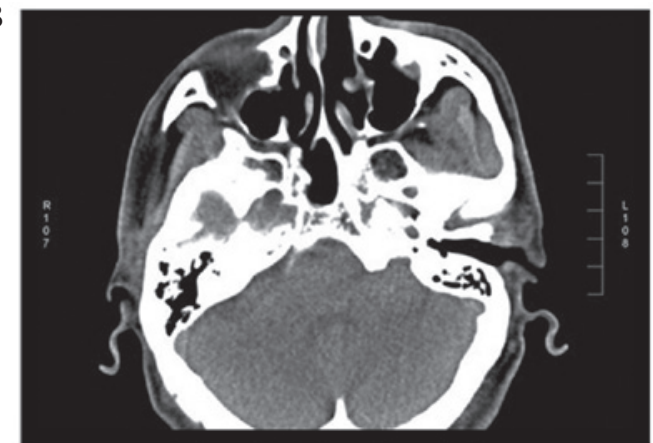

Figure 1. High-resolution computed tomography scans showing (A) a mass located in the left parapharyngeal space, and (B) with no tumor in the cerebellopontine angle.

A

B

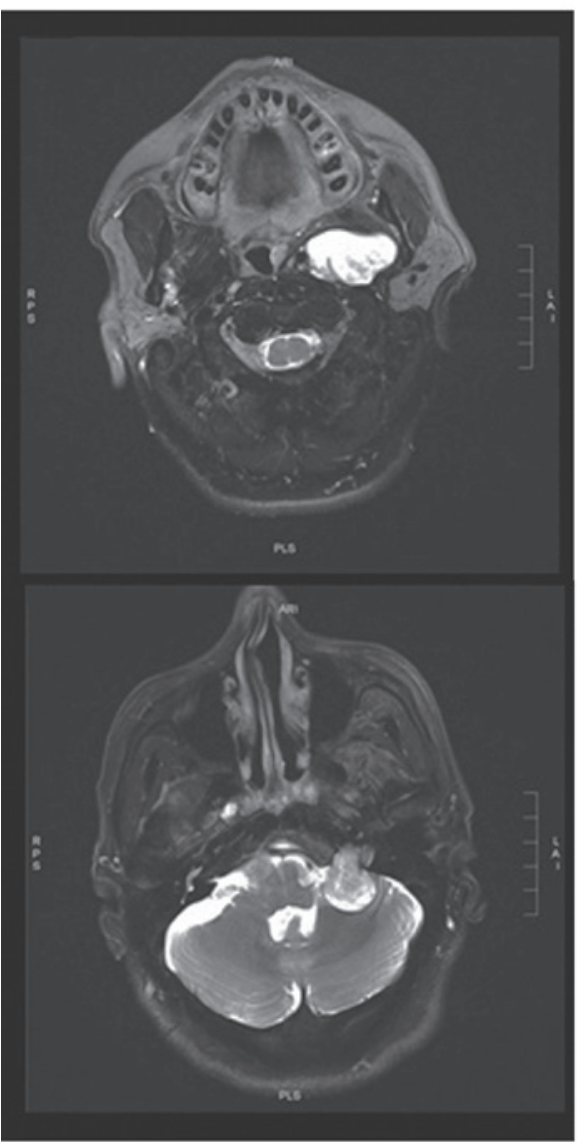

C

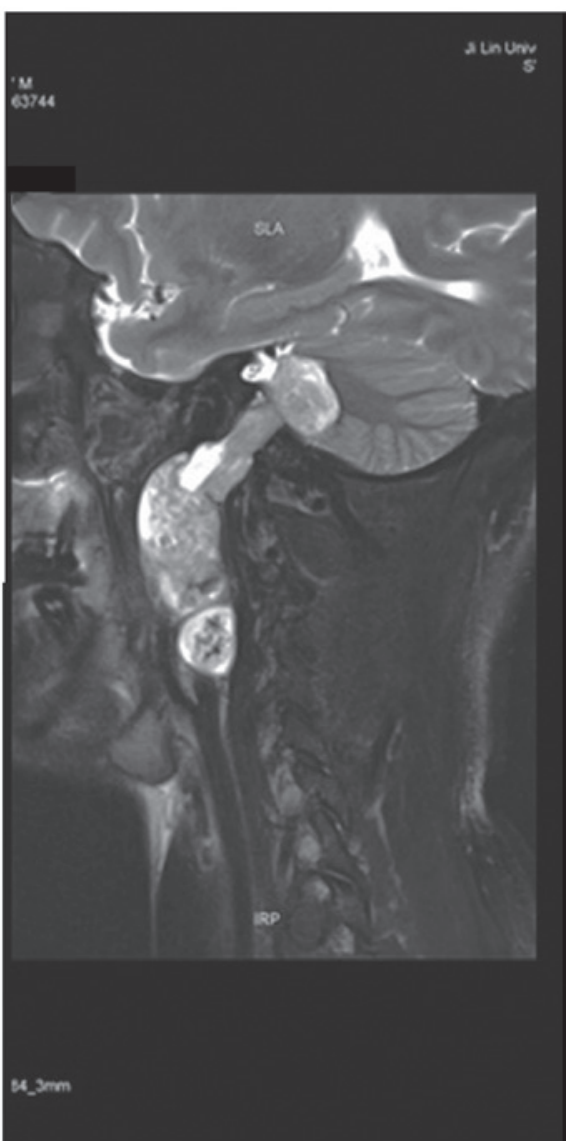

Figure 2. Dumbbell-shaped tumor located in (A) the left parapharyngeal space and (B) the left cerebellopontine angle. (C) The tumor showed inhomogeneous signal intensity on $\mathrm{T} 2$-weighted magnetic resonance imaging.
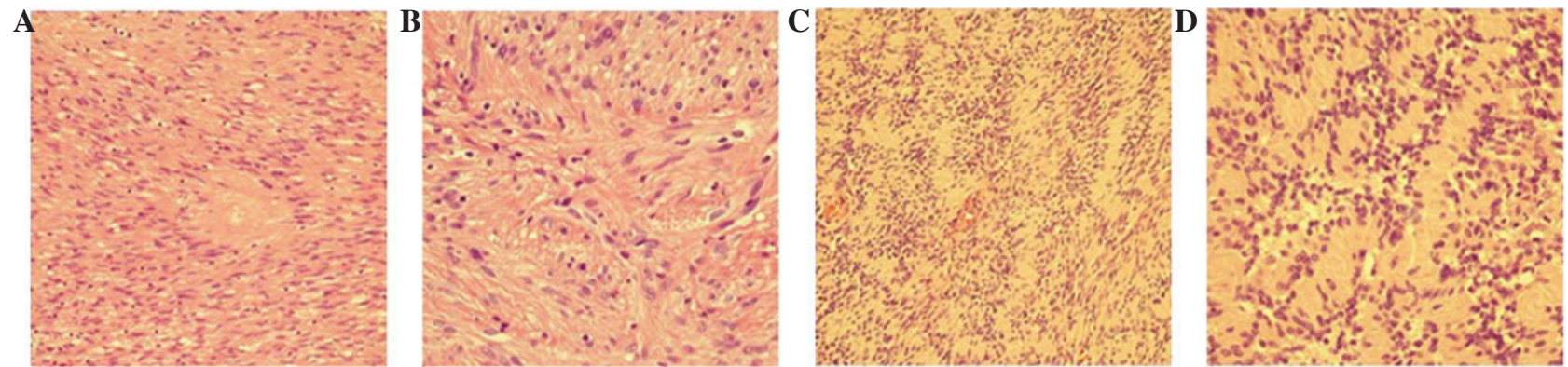

Figure 3. Initial extracranial tumor: Photomicrograph showing spindle-shaped tumor cells stained with Hematoxylin and eosin at (A) x20 and (B) x40 magnification. For recurrent dumbbell-shaped tumor: Histological appearance of the lesion at (C) x20 and (D) x40 magnification showing the showing typical spindle-shaped tumor cells, with nuclear palisading and relatively thin-walled vessels. Mitotic figures were increased and nuclear atypia was limited. 
tongue, a weakened left pharyngeal reflex and left vocal cord paralysis consistent with palsy of the hypoglossal, glossopharyngeal and recurrent nerves. Subsequent magnetic resonance imaging demonstrated a solitary extra- and intracranial tumor in the left parapharyngeal space and the cerebellopontine angle, in contact with the enlarged hypoglossal nerve canal. The tumor mass extended extracranially to the C4 level, and was $\sim 9.5 \times 4.4 \times 3.4 \mathrm{~cm}$ (Fig. 2), which to the best of our knowledge, is the biggest hypoglossal schwannoma reported to date. Following the completion of pre-operative preparations, the giant tumor was completely removed in a one-stage surgical procedure via the far-lateral suboccipital approach combined with the transcervical approach. Histopathology revealed a relatively cellular schwannoma with cystic degeneration and hemorrhage (Fig. 3A and B), immunohistochemical examination demonstrated positivity for S-100 protein, and that the positive expression rate of $\mathrm{Ki}-67$ was higher in the recurrent tumor cells than the initial tumor cells (3 vs. <1\%) (Fig. 3).

One year later, the patient was reexamined and no signs of tumor recurrence were found. Upon neurological examination, no deficits were noted, with the exception of persistent palsy of the left hypoglossal nerve. Two years later, the patient was reexamined and no signs of tumor recurrence were observed in the MRI image, during this period the patient did not receive any further treatment.

\section{Discussion}

Schwannomas are benign, slow-growing tumors of the myelin-producing Schwann cells. Hypoglossal schwannomas typically arise intracranially, prior to causing enlargement and erosion of the hypoglossal canal, and then finally extending extracranially. According to the classification of jugular foramen neurinomas described by Kaye et al (17), the hypoglossal schwannomas recorded in the literature can be divided into 3 types: Type A, intracranial in $31.5 \%$; type B, dumbbell-shaped or extra- and intracranial in 50\%; and type $\mathrm{C}$, extracranial in $18.5 \%$ (3).

Certain neurologists consider that the extracranial portion of dumbbell-shaped hypoglossal schwannomas does not require resection; however, in our opinion, a complete surgical resection is indicated if the tumor becomes symptomatic or when marked growth is noted, according to the condition of the patient, and should be performed via a one or two stage procedure According to a previous study (12), a complete tumor resection is achieved in $<30 \%$ of these dumbbell-shaped hypoglossal schwannomas. Although little is known with regard to the long-term natural history of residual hypoglossal schwannoma, the growth rate of schwannoma is generally considered to be slow, however, this growth will compress vessels and nerves, and more aggressive adherence will occur, causing complications such as dysphagia and respiratory disturbance (5). Further surgery or radiosurgery may later be required if additional growth of the extracranial region of the tumor occurs. Radiosurgery is not necessarily harmless if the tumor is compressing the brainstem. In the present case, however, the tumor recurred markedly 6 months after the first surgery. Worst of all, severe adhesions of the recurrent tumor to the brain stem, lower cranial nerve and left internal carotid artery were apparent.
Notably, the tumor arose extracranially and then extended intracranially. The recurrence emerged with cystic degeneration and hemorrhage, unlike the initial tumor, and residual cystic hypoglossal schwannoma are known to exhibit a tendency for accelerated regrowth (5).

In our opinion, a complete surgical resection is indicated if the tumor becomes symptomatic or when marked growth is noted, according to the condition of the patient, and should be performed via a one- or two-stage procedure. The most recent preferential surgical approach is a far lateral approach with a partial resection of the condyle to open the hypoglossal canal $(3,16)$. In order not to destroy the condyle and induce craniocervical instability, in the present study, a far lateral suboccipital approach (no drilling of the hypoglossal canal) in combination with a transcervical approach was used to resect the intra- and extracranial region of the tumor in a one-stage procedure. A tracheotomy was performed prior to the surgery to prevent post-operative dyspnea and aspiration. Following the surgery, the patient's symptoms improved markedly, without causing any additional damage. This indicated that the treatment decision was correct, however, such a procedure requires experience and a prolonged surgical duration.

Overall, the choice of management strategy for benign cranial base tumors in the elderly population is difficult due to the depth of the lesion site and the vicinity of complex neurovascular structures, yet such situations will be encountered more frequently in the near future as a result of the increasing elderly population. For the management of benign cranial base tumors, particularly in patients with giant recurrent tumors and an advanced age, an individual end-point of surgery should be considered, taking into account the life expectancy of the patient and the natural course of the disease (16). Additional studies on hypoglossal schwannomas are required, particularly cases in which the hypoglossal schwannoma was not totally resected, not only in order to develop more definitive and secure surgical treatments, but also to reduce the resultant unnecessary suffering of patients.

\section{Acknowledgements}

The present study was supported by the Young Scientists Fund of the National Natural Science Foundation of China (grant no. 21401072).

\section{References}

1. De Martel T, Subirana A and Guillaume J: Los tumores de le fosa cerebral posterior: Voluminoso neurinoma del hipogloso con desarrollo juxtabulbo-protuberancial. Operacioncuracion Ars Med 9: 416-419, 1933.

2. Baghel PS, Gupta A, Tripathi VD and Reddy DS: Hypoglossal schwannoma presenting as hemi-atrophy of the tongue. Neurol India 61: 324-325, 2013.

3. Hoshi M, Yoshida K, Ogawa K and Kawase T: Hypoglossal neurinoma-two case reports. Neurol Med Chir (Tokyo) 40: 489-493, 2000.

4. Jia G, Wang Z and Zhang J: Diagnosis and treatment of hypoglossal neurinoma. Zhonghua Yi Xue Za Zhi 81: 1264-1265, 2001 (In Chinese).

5. Li WC, Hong XY, Wang LP, Ge PF, Fu SL and Luo YN: Large cystic hypoglossal schwannoma with fluid-fluid level: A case report. Skull Base 20: 193-197, 2010.

6. Kuo LT, Huang AP, Kuo KT and Tseng HM: Extradural dumbbell schwannoma of the hypoglossal nerve: A case report with review of the literature. Surg Neurol 70: 34-39, 2008. 
7. Mariniello G, Horvat A, Popovic M and Dolenc VV: Cellular dumbbell schwannoma of the hypoglossal nerve presenting without hypoglossal nerve palsy. Clin Neurol Neurosurg 102: 40-43, 2000.

8. Rachinger J, Fellner FA and Trenkler J: Dumbbell-shaped hypoglossal schwannoma. A case report. Magn Reson Imaging 21: $155-158,2003$.

9. Kadri PA and Al-Mefty O: Surgical treatment of dumbbell-shaped jugular foramen schwannomas. Neurosurg Focus 17: E9, 2004

10. Aihara K and Morita A: Dumbbell-shaped hypoglossal schwannoma in an elderly woman: A clinical dilemma. Surgical Neurol 63: 526-528, discussion 528, 2005.

11. Kabatas S, Cansever T, Yilmaz C, Demiralay E, Celebi S and Caner H: Giant craniocervical junction schwannoma involving the hypoglossal nerve: Case report. Turk Neurosurg 20: 73-76, 2010.

12. Zhang Q, Kong F, Guo H, Chen G, Liang J, Li M and Ling F: Surgical treatment of dumbbell-shaped hypoglossal schwannoma via a pure endoscopic transoral approach. Acta Neurochir (Wien) 154: 267-275, 2012.
13. Oyama H, Kito A, Maki H, Hattori K, Noda T and Wada K: Schwannoma originating from lower cranial nerves: Report of 4 cases. Nagoya J Med Sci 74: 199-206, 2012.

14. Santarius T, Dakoji S, Afshari FT, Raymond FL, Firth HV, Fernandes HM and Garnett MR: Isolated hypoglossal schwannoma in a 9-year-old child. J Neurosurg Pediatr 10: $130-133,2012$.

15. Inoue $\mathrm{H}$, Nakagawa $\mathrm{Y}$, Ikemura M, Usugi E, Kiyofuji $\mathrm{Y}$ and Nata M: Acute brainstem compression by intratumoral hemorrhages in an intracranial hypoglossal schwannoma. Leg Med (Tokyo) 15: 249-252, 2013.

16. Sarma S, Sekhar LN and Schessel DA: Nonvestibular schwannomas of the brain: A 7-year experience. Neurosurgery 50: 437-448, 2002.

17. Kaye AH, Hahn JF, Kinney SE, Hardy RW Jr and Bay JW: Jugular foramen schwannomas. J Neurosurg 60: 1045-1053, 1984. 